\title{
Do GP Registrars Care about QOF? An Audit of General Practice Registrar Quality and Outcome Framework Achievement
}

\section{Carter Singh ${ }^{1-3^{*}}$}

${ }^{1}$ GP Partner Willowbrook Medical Practice, UK

2NHS Mansfield \& Ashfield CCG Governing Body GP Board Member, UK

${ }^{3}$ NHS Mansfield \& Ashfield CCG Audit \& Clinical Governance GP Clinical Lead, UK

*Corresponding author: Carter Singh, GP Partner Willowbrook Medical Practice, UK, Tel: 07814737426; E-mail: g777cartersingh@yahoo.co.uk

Received date: January 25, 2017; Accepted date: February 27, 2017; Published date: February 28, 2017

Copyright: (c) 2017 Singh C. This is an open-access article distributed under the terms of the Creative Commons Attribution License, which permits unrestricted use, distribution, and reproduction in any medium, provided the original author and source are credited.

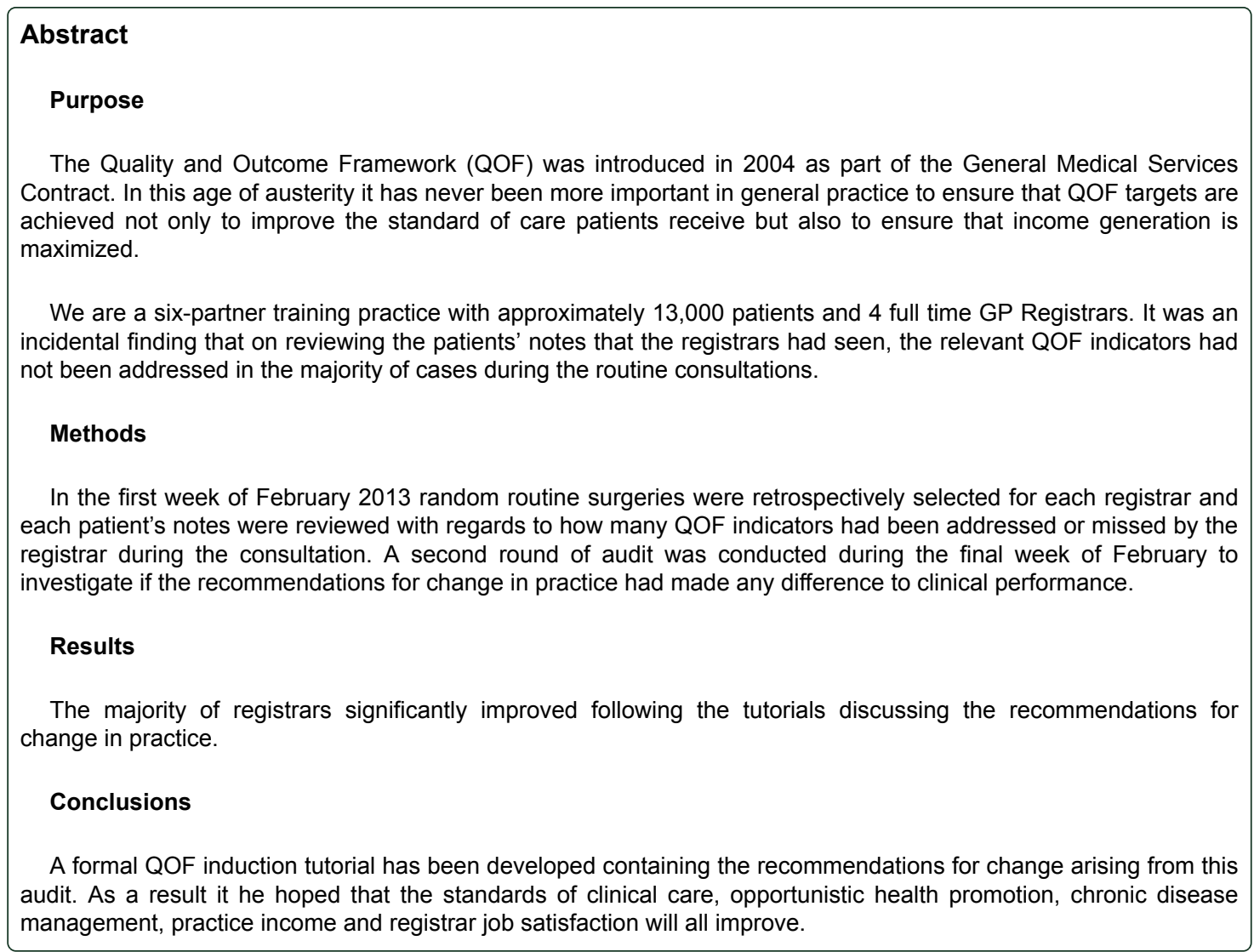

Keywords: Quality and outcome framework; Health promotion; GP Registrars

\section{Introduction}

The Quality and Outcome Framework (QOF) was introduced in 2004 as part of the General Medical Services Contract. It is a voluntary incentive scheme for General Practices in the UK, providing financial rewards for attainment of indicator targets [1]. The QOF contains groups of indicators, against which practices score points according to their level of achievement. The higher the score, the higher the financial reward for the practice. (http://www.nice.org.uk/aboutnice/qof/)

In this age of austerity it has never been more important in general practice to ensure that QOF targets are achieved not only to improve the standard of care patients receive but also to ensure that income generation is maximized.

We are a six-partner Nottinghamshire training practice with approximately 13,000 patients and 4 full time GP Registrars. All of our registrars receive an induction prior to embarking upon performing clinical work in our practice. Each registrar has their own GP trainer.

The induction includes detailed explanations of the QOF and the methods by which to record the QOF indicator achievement on the clinical system (SystmOne).

It was an incidental finding during registrar debriefs that on reviewing the patients' notes that the registrars had seen, the relevant QOF indicators had not been addressed in the majority of cases during the routine consultations. It was decided therefore to audit this topic as 
if it continued it could have a significant adverse effect on the standards of patient care and practice income [2].

The QOF encompasses a range of RCGP 'Clinical Priority' areas including, Respiratory, Child Health, Diabetes, and Cancer so was identified as being an ideal area to audit. The audit is also designed to improve the quality of training for future GPs and therefore aligned with another important RCGP priority.

There is no literature that can be identified which exists that has addressed this clinical topic. After performing a comprehensive literature search there are no clinical standards relating to GP Registrar QOF achievement which have been set by and regulatory body or committee.

The standards we have set in our practice are that there are no reasons why our registrars should not be addressing all appropriate QOF indicators. We understand there are some QOF indicators which are more appropriately dealt with by our practice nurses in the routine chronic disease monitoring clinics $[1,3]$.

\section{Methods}

In the first week of February 2013 (two months into all of the registrars' placements) random routine surgeries were retrospectively selected for each registrar and each patient's notes were reviewed in regards to how many QOF indicators had been addressed or missed by the registrar during the consultation.

The registrars were not informed about which clinic session was chosen to ensure that they would not alter their usual style of consulting.

Once the data was collated and analyzed, an individual discussion was had with each registrar about their performance and any difficulties they were having with meeting the QOF targets [4].

Individual concerns and issues were addressed and the registrars agreed to make a concerted effort to be more aware of QOF and view it as part of their routine practice rather than an optional-extra.

A second round of audit was conducted during the final week of February to investigate if the recommendations for change in practice had made any difference to clinical performance [5].

\section{Results}

\begin{tabular}{|c|c|c|c|}
\hline & $\begin{array}{l}\text { Total Number of } \\
\text { Patients in Clinic }\end{array}$ & $\begin{array}{l}\text { Number of Patients } \\
\text { Requiring QoF Work }\end{array}$ & $\begin{array}{lll}\text { Number } & \text { of } & \text { QoF } \\
\text { Targets } & \text { Missed } & \text { per } \\
\text { Patient } & & \end{array}$ \\
\hline $\begin{array}{l}\text { OA } \\
\text { (ST3) }\end{array}$ & 17 & 12 & 2.00 \\
\hline $\begin{array}{l}\text { RS } \\
\text { (ST3) }\end{array}$ & 17 & 11 & 1.72 \\
\hline $\begin{array}{l}\text { PS } \\
\text { (ST1) }\end{array}$ & 13 & 7 & 3.71 \\
\hline $\begin{array}{l}\text { CV } \\
\text { (ST1) }\end{array}$ & 13 & 7 & 1.85 \\
\hline
\end{tabular}

Table 1: First round of data collection.

\begin{tabular}{|l|l|l|l|l|}
\hline \multicolumn{3}{|c|}{$\begin{array}{l}\text { Chart Showing Number of Qof Items Not } \\
\text { Checked Per Patient }\end{array}$} \\
\hline
\end{tabular}

Table 2: Second round of data collection.

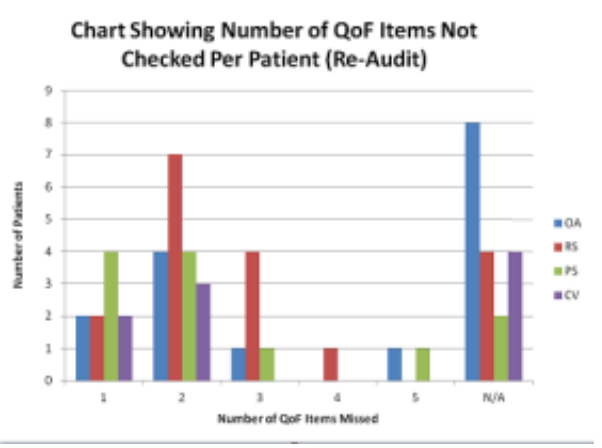

Figure 2: Second round of data collection.

\begin{tabular}{|l|l|}
\hline & $\begin{array}{l}\text { Percentage Change between the First } \\
\text { and Second Rounds of Data Collection } \\
(\%)\end{array}$ \\
\hline OA (ST3) & 77 \\
\hline RS (ST3) & 75 \\
\hline PS (ST1) & 86 \\
\hline CV (ST1) & 39 \\
\hline
\end{tabular}

Table 3: Changes in registrar performance between the first and second rounds of data collection. 


\section{Discussion and Conclusion}

The recommendations for change in practice were implemented between the first and second audit cycles. These recommendations were based on issues and themes arising from discussion with registrars after the first round of data collection (Table 1), (Figure 1), [6]. The recommendations were imparted to the registrars in a one-toone tutorial addressing the difficulties the registrars were encountering with the QOF.

One reason quoted for not addressing the QOF during routine consultations was insufficient time to deal effectively with patient's presenting complaint and the QOF targets in addition. Wider issues relating to time-management were discussed and strategies to help with addressing the QOF were practically demonstrated.

Another reason for poor QOF performance was insufficient knowledge on how to record that the QOF indicator attainment had been dealt with on the computer system. Our 'QOF practice templates' have been specifically designed for this purpose. The templates are entitled by clinical area and contain all of the relevant read-codes and explanatory notes which are required by the QOF rules $[6,7]$.

Some registrars were unsure where the QOF reminders were on the computer screen. These registrars were shown on the computer screen that the QOF reminders were located on the patients' home screens and were present as yellow icons in the top right corner of the screen and were accessible at any time during the consultation. They were also shown that by clicking on the reminder automatically opened up the relevant template.

Achieving QOF targets was perceived by some of the registrars as a 'box ticking exercise' rather than as a tool used to improve the standards of patient care. A discussion was had with the registrars exploring holistic healthcare and the importance of opportunistic health promotion and the management of chronic diseases in primary care.

There was some sentiment amongst the registrars that there was no direct financial incentive for them to achieve the QOF targets and it was felt that if there was individual performance-related payment they would perform better. It was explained to the registrars that the remuneration for all aspects of patient care were incorporated into their salaries [8]. This includes the QOF and enhanced services the practice offers. A wider discussion was had about teamwork, work ethic and attitudes.

It can be seen from the second round of data collection that the majority of registrars significantly improved following the tutorials discussing the recommendations for change in practice (Table 2), (Figure 2). A discussion was had with the registrar who significantly worsened after the recommendations for change in practice tutorial. The reason she gave for not addressing the QOF during routine consultations was that she was 'not focused'. She declined to elaborate any further [9-11]. This was discussed with her trainer and further training needs was identified for this registrar and concerted efforts are being made to assist her further.

A formal QOF induction tutorial has been developed containing the recommendations for change arising from this audit. This induction tutorial will be incorporated into all registrars' inductions before they embark upon clinical work at our practice $[12,13]$. As a result it is hoped that the standards of clinical care, opportunistic health promotion, chronic disease management, and practice income and registrar job satisfaction will all improve.

\section{References}

1. (1989) Secretaries of State for Health, Wales, Northern Ireland, and Scotland. Medical audit. Working Paper 6. London: HMSO.

2. Fraser RC, Baker RH, Lakhani MK (1998) Evidence-based clinical audit: an overview. En: Evidence-based audit in general practice. Fraser RC, Lakhani MK, Baker RH eds. Butterworth-Heinemann. Oxford. P: 1-15.

3. Marinker M (1990) Principles. In: Medical audit and general practice. Marinker M ed. BMJ Publishing Group. London. P: 1-14.

4. Crombie IK, Davies HTO, Abraham SCS, Florey CduV (1993) The Audit Handbook. John Wiley and Sons. Chichester, UK.

5. Foster A, Ratchford D, Taylor D (1994) Auditing for patients. Quality in Health Care 3: s16-s19.

6. St Leger AS, Schnieden H, Walsworth-Bell JP (1993) Using routinely gathered data to assist in evaluation. En: Evaluating health services effectiveness. A guide for health professionals, service managers and policy makers. Open University Press. Buckingham, UK. P: 29-57.

7. Bowling A (1997) Evaluating health services. En: Research methods in health: Investigating health and health services. Open University Press. Buckingham, UK. P: 5-16.

8. Batstone GF (1990) Educational aspects of medical audit. BMJ 301: 326-328.

9. Shaw CL (1980) Aspects of audit. 4: Acceptability of audit. BMJ 280: 1443-1446.

10. Duthie RB (1993) Audit: historical and future perspectives. In: Medical audit rationale and practicalities. Frostick S, Ratford PJ, Wallace A eds. Cambridge University Press. Cambridge. P: 5-17.

11. Hey Groves EW (1908) Surgical statistics: a plea for uniform registration of operation results. BMJ 2: 1008-1009.

12. Shaw CL (1980) Aspects of audit 5: Looking forward to audit. BMJ 280: 1509-1511.

13. Frostick S, Ratford PJ, Wallace A (1993) Introduction. En: Medical audit rationale and practicalities. Frostick S, Ratford PJ, Wallace A eds. Cambridge University Press. Cambridge. P: 1-4. 